\title{
A história de vida como instância metódico-técnica no campo da Comunicação
}

LIFE STORY AS A METHODICAL-TECHNICAL SPHERE IN THE FIELD OF COMMUNICATION

\section{Monica Martinez}

Docente do Programa de Mestrado em Comunicação e Cultura da Universidade de Sorocaba (Uniso). Doutora em Ciências da Comunicação pela Escola de Comunicações e Artes da Universidade de São Paulo com pós-doutorado em Narrativas Digitais pelo Programa de Pós-Graduação em Comunicação Social da Faculdade de Comunicação da Universidade Metodista de São Paulo e estágio de pesquisa junto ao departamento de Rádio, Televisão e Cinema da Universidade do Texas.

E-mail: martinez.monica@uol.com.br

Recebido em 11 de março de 2014. Aprovado em 25 de agosto de 2014

\section{Resumo}

Este texto analisa a história de vida como instância metódico-técnica de pesquisa em Comunicação. Focaliza as origens da prática, estabelecendo seus vínculos com o campo, em especial o Jornalismo. Reflete sobre o uso da história de vida em outras áreas do conhecimento, em particular a Sociologia e a História Oral. Aponta sua possível usabilidade e, sobretudo, seus limites. Finalmente, sugere a impossibilidade do registro em bases objetivas ou amparado no conceito de verdade absoluta, uma vez que a fonte primária destas coletas são seres humanos, paradoxais e idiossincráticos por natureza.

Palavras-chave: Comunicação, Narrativas, História de Vida.

\section{Abstract}

The aim of this paper is to analyze life story as a methodical and technical sphere of Communication research. It focuses on the origins of the practice, establishing its links with the field, especially Journalism. It reflects on the use of life history in other areas of knowledge, particularly Sociology and Oral History. It points out its possible usability and limits. It suggests the impossibility of the record in an objective basis or supported by the concept of an absolute truth, since the primary source of these collections are human beings.

Keywords: Communication, Narratives, Life History. 


\section{Sobre histórias e vidas}

A história de vida, enquanto uma técnica de pesquisa qualitativa, tem sido empregada quando se busca a compreensão com profundidade e particularidade do comportamento de indivíduos e grupos sociais. Por meio dela, os dados são "coletados preferencialmente nos contextos em que os fenômenos são construídos", permitindo desenvolver a análise "no decorrer do processo de levantamento", com "enfoque na compreensão e na interpretação à luz dos significados dos próprios sujeitos e de outras referências afins da literatura", o que faz que a teoria seja "construída por meio da análise dos dados empíricos" - embora os estudos qualitativos possam "partir de categorias preexistentes" (DIEHL; TATIM, 2004, p. 52).

Atualmente sua utilização é comum em vários campos científicos. Trata-se de “(...) uma técnica de pesquisa social utilizada pelos antropólogos, sociólogos, psicólogos, educadores e outros estudiosos, como fonte de informação para seus trabalhos" (MARCONI; LAKATOS, 2012, p. 122-123). Convém lembrar, no entanto, que essa abordagem qualitativa emerge no final do século XIX. Os “(...) estudos dos antropólogos nas sociedades 'primitivas' foram determinantes para o desenvolvimento das técnicas de pesquisa que permitem recolher diretamente observações e informações sobre a cultura nativa", diz a antropóloga brasileira Miriam Goldenberg (1999, p. 20). Ela lembra que estas sociedades eram de pequenas dimensões, situavam-se em locais isolados e não dispunham de escrita - pelo menos não uma que o pesquisador, a princípio, dominasse. Mais tarde, expoentes da área, como o antropólogo teuto-estadunidense Franz Boas (1858-1942), falaria da importância das anotações de campo (idem, p. 21).

Contudo, talvez não estivesse nos destinos longínquos, mas nas emergentes cidades, a prática que definitivamente influenciaria a técnica da história de vida: a entrevista jornalística. Seu uso também principia mais ou menos no mesmo período, isto é, no final do século XIX. O jornalista e docente Mário de Lucca Erbolato - um dos fundadores do curso de Jornalismo da PUC-Campinas, em São Paulo - refere-se à entrevista pioneira feita para o New York Sun em 1836 pelo repórter James Gordon Bennet com a proprietária de um prostíbulo, onde teria ocorrido um crime (ERBOLATO, 1984, p. 138).

O fato é que a veiculação de entrevistas na mídia impressa e, posteriormente, no rádio, populariza o gênero, integrando-o aos hábitos urbanos contemporâneos (MEIHY, 1998, p. 27). E ele se torna popular por vários motivos. Um deles é a facilidade de se colher informações de indivíduos que não sabem escrever, por exemplo (GOLDENBERG, 1999, p. 20). Registros sonoros, como os possibilitados pelo surgimento do rádio, adicionados, mais tarde, aos visuais, como os propiciados pelo cinema e pela televisão (e a 
consequente convergência posteriormente pela mídia digital) permitem ao receptor a sensação de ter acesso direto ao entrevistado. Ainda que essa percepção seja, na maioria das vezes, ilusória - uma vez que entre uns e outros existem os filtros do aparato midiático terciário, como define Harry Pross (1923-2010), teórico de mídia alemão (BAITELLO, 2005, p. 31-35).

Ainda sobre jornalismo, vale lembrar que a revista The New Yorker, lançada em 1925, é um dos baluartes mundiais da história de vida ou, termo mais comum em jornalismo, do perfil (do inglês profile). Seu quarto editor ${ }^{1}$ desde então, David Remnick, afirma que se o perfil como peça biográfica não foi uma invenção da New Yorker, ela decididamente o levou à condição de arte (REMNICK, 2000). No caso brasileiro contemporâneo, expoente deste perfil trabalhado é a revista piauí, da editora Abril.

Grandes reportagens como a feita pelo repórter estadunidense James Agee (19091955) e o fotógrafo Walker Evans (1903-1975) para a revista Fortune sobre os efeitos da Grande Depressão no Alabama, localizado no sul dos Estados Unidos, também tinham esse caráter de serem baseadas nas histórias de vida de três famílias, escolhidas por serem representativas do ponto de vista socio-histórico. Convém ressaltar que na época a reportagem foi rejeitada pelo editor da Fortune. "Precisamente porquê, ninguém pode dizer com certeza - não há carta do editor, nenhuma prova que ele se recusou a cooperar, nada limpo e organizado de nenhum dos lados"2 (HASLETT, 2013, p. 17). Revista e ampliada, a reportagem foi lançada em formato de livro em 1941, com o título de Elogiemos os Homens Ilustres (Let us Praise Famous Man). Em 2013, 77 anos depois da rejeição, seu manuscrito original foi descoberto e o relato original lançado em inglês pela editora Baffler and Melville House.

\section{Robert Park: um elo entre o Jornalismo e as Ciências Sociais}

Nascido em 1928, o sociólogo estadunidense Howard S. Becker conta que a Universidade de Chicago não foi a mesma depois da chegada de Robert Ezra Park (18641944) ao departamento de sociologia. Depois conhecido como Escola de Chicago, o departamento "promoveu vigorosamente esta perspectiva durante a década de vinte. Quase todos os estudos fizeram uso de documentos pessoais" (BECKER, 1999, p. 101).

1 O fundador da publicação, Harold Ross, manteve a posição até sua morte, em 1951. De 1951 a 1987, assume William Shawn (1907-1992), lendário pela precisão de seu trabalho. Ele é substituído por Robert Gottieb (1987-1992), quando a Advance Publications, pertencente ao grupo Conde Nast, adquire o título. Tina Brown precede Remnick na posição de 1992 a 1998 (Nota da autora).

2 Em tradução livre da autora. 
Segundo Becker, "o primeiro documento sociológico sobre história de vida que chamou amplamente a atenção remonta a 1918, quando o sociólogo polonês Florian Znaniecki (1882-1958), convidado pelo sociólogo estadunidense William Isaac Thomas (1863-1947), da Universidade de Chicago, publicaram o primeiro dos cinco volumes de The Polish Peasant in Europe and America (idem), em português $O$ Camponês Polonês na Europa e América.

A formação de Park foi central neste encorajamento do uso científico dos relatos pessoais. Explica-se. Durante a graduação na Universidade de Michigan, influenciado pelo filósofo e psicólogo John Dewey (1859-1952), Park desenvolveu apreço pelas causas sociais, tendo em seguida trabalhado por 11 anos como jornalista, dos 23 aos 34 anos (1887 a 1898), até prosseguir a carreira acadêmica. Tornou-se mestre por Harvard em 1899 e doutor em filosofia por Heidelberg, na Alemanha, em 1903. Por dois anos, 1904 e 1905, ele foi professor assistente de filosofia em Harvard, até aceitar o cargo de assessor de imprensa no Instituto Tuskegee, ligado a causas dos afrodescendentes, em particular à Educação, onde se tornaria diretor de Relações Públicas. Em 1914, primeiro como professor e depois como titular, ele chegaria à Universidade de Chicago e ficaria na instituição até se aposentar, em 1933. A Chicago dos anos 1920, com seu cadinho humano, revelou-se o laboratório ideal para que Park desenvolvesse sua proposta da Ecologia Humana (ASA, 2013). Ele entendia que a cidade não é apenas um mecanismo físico, artificial. Antes, os indivíduos comprimidos em espaços urbanos geram um meio ambiente vivo e pulsante, como os demais encontrados no mundo natural. Cenário, portanto, ideal para se estudar os fenômenos das mediações humanas, com ou sem aparatos, por meio de técnicas como a história de vida.

Embora o uso da história de vida tenha tido bases muito concretas e práticas, tendo sua praticidade atestada em pesquisa por The Polish Peasant, ele estava teoricamente bem embasado na psicologia social do filósofo estadunidense Georg Herbert Mead (1863-1931). No Brasil, um dos pesquisadores da área de psicologia social a fazer esta aproximação é Eclea Bosi, da Universidade de São Paulo. Ao tratar da relação entre o psiquismo e a sociedade, ela se apoia em alguns autores como o filósofo francês Henry Bergson (1859-1941) para discutir as funções da memória - um conceito vital em história de vida (BOSI, 1994).

$\mathrm{Na}$ Universidade de Chicago, a história de vida possuía outros defensores influentes, como o sociólogo canadense Ernest W. Burgess (1885-1966). O resultado é que a história de vida gozou de grande popularidade, sendo um dos principais instrumentos de pesquisa - embora certamente não o único - adotado por aquele departamento (BECKER, 1999, p. 103).

Becker apresenta a ideia do mosaico em história de vida. Para compreendê-la, no entanto, é útil fazer uma pequena digressão sobre o próprio conceito da técnica. Embora 
seja mais comumente empregado o termo no singular, "história de vida", é importante ressaltar que este instrumento de pesquisa "privilegia a coleta de informações contidas na vida pessoal de um ou vários informantes" (SEVERINO, 2007, p. 125). Seria, neste segundo caso, histórias de vida. Quanto ao formato, pode "assumir formas variadas: autobiografia, memorial, crônicas, em que se possa expressar as trajetórias pessoais dos sujeitos" (idem). O foco da narrativa, no entanto, está no protagonista.

Em Comunicação, e em particular no Jornalismo, esse recurso de captação aparece na "forma clássica da entrevista - como a reprodução do diálogo entre o entrevistador e o entrevistado - ou como depoimento direto" (LIMA, 2009, p. 114). Há ainda uma terceira via, "em que se combinam essas modalidades de apresentação com narrativa em primeira ou terceira pessoa" (idem). A combinação com outras técnicas, como a observação participante, faria da história de vida um "poderoso recurso para a melhoria dos processos de captação dos jornalistas (...), uma vez que utiliza a vivência do entrevistado de maneira longitudinal, buscando encontrar padrões de relações humanas e percepções individuais, além de interpretações sobre a origem e o funcionamento dos fenômenos sociais (BUITONI apud LIMA, 2009, p. 93).

Neste contexto, a ideia da área de Ciências Sociais de mosaico é interessante, uma vez que a "imagem do mosaico é útil para pensarmos sobre este tipo de empreendimento científico. Cada peça acrescentada num mosaico contribui um pouco para nossa compreensão do quadro como um todo" (BECKER, 1999, p. 104). Nesta premissa, o destaque fica para a questão da relação: "Quando muitas peças já foram colocadas, podemos ver, mais ou menos claramente, os objetos e as pessoas que estão no quadro, e sua relação uns com os outros" (idem). Não há, contudo, a expectativa ilusória da objetividade; antes, há $\boldsymbol{a}$ busca da compreensão da unidade na diversidade: "Diferentes fragmentos contribuem diferentemente para nossa compreensão: alguns são úteis por sua cor, outros porque realçam os contornos de um objeto" (ibidem). Para Becker, a concepção do mosaico não se insere no contexto do funcionalismo: "Nenhuma das peças tem uma função maior a cumprir, se não tivermos sua contribuição, há ainda outras maneiras para chegarmos a uma compreensão do todo" (BECKER, 1999, p. 104-105).

No âmbito da memória coletiva, ocorre um diálogo interessante da perspectiva sociológica com a História Oral, como veremos a seguir.

\section{História Oral: um método útil e preciso}

Do ponto de vista histórico o método da história oral surge em 1947, na Universidade de Colúmbia, em Nova York. "Allan Nevins organizou um arquivo e oficializou o termo que passou a ser indicativo de uma nova postura diante do uso e divulgação 
de entrevistas" (MEIHY, 1998, p. 27). Segundo Meihy, isso "se deu depois da guerra, quando combinaram os avanços tecnológicos com a necessidade de se propor formas de captação de experiências importantes como as vividas então por combatentes, familiares e vítimas dos conflitos" (idem).

$\mathrm{O}$ método se desenvolve na segunda metade do século XX, um século que seria dividido em três eras pelo historiador inglês Eric Hobsbawn: a da catástrofe das duas grandes guerras, a dos anos dourados das décadas de 1950 e 1960 e a era do desmoronamento final, entre 1970 a 1991 (HOBSBAWN, 2008). Neste contexto turbulento, e não por acaso, o historiador inglês Paul Thompson, um dos expoentes da história oral, aponta que por meio da história "as pessoas comuns procuram compreender as revoluções e mudanças por que passam em sua própria vida" (THOMPSON, 2002, p. 21).

No Brasil, a história oral começa a ser empregada com êxito em 1975 por pesquisadores do Centro de Pesquisa e Documentação de História Contemporânea do Brasil da Fundação Getúlio Vargas do Rio de Janeiro [CPDOC-FGV] (CAPRINO; PERAZZO, 2011, p. 802). Desde então, outros centros passam a empregar o método, caso do Centro de Estudos Rurais e Urbanos (Ceru) da Universidade de São Paulo (USP), do Museu da Pessoa, em São Paulo, e, mais recentemente, do Memórias do ABC-Núcleo de Pesquisas e de Produções Midiáticas da Universidade Municipal de São Caetano do Sul (USCS), entre outros.

Do ponto de vista técnico propriamente dito, a história oral é um conjunto de procedimentos com oito etapas bem definidas (MEIHY, 1998, p. 24):

1. Elaboração de um projeto;

2. Definição de um grupo de pessoas a serem entrevistadas;

3. Planejamento da condução das gravações;

4. Passagem do material em áudio para escrita (chamado de transcrição);

5. Conferência do depoimento com o entrevistado;

6. Obtenção de autorização para o uso;

7. Arquivamento;

8. Publicação dos resultados, de forma a serem preferencialmente disponibilizados ao grupo que concedeu as entrevistas.

Ressalta-se a escuta atenta, sem demasiada interferência do entrevistador. O próprio recurso da gravação “(...) resulta numa alta fidelidade à fala do personagem, permitindo utilizar diálogos e expressões pessoais que deixam a narrativa saborosa, ajudando a compor a persona do indivíduo ou grupo social" (MARTINEZ, 2008, p. 28). É 
preciso lembrar que, embora disponíveis em inglês, em versões pagas, até hoje não há ferramentas eficientes de transcrição automática de áudio para texto em português. Este trabalho de transcrição literal pode ser facilitado por meio de alguns programas gratuitos como o Transcribe (www.transcribe.wreally.com), porém segue sendo um dos mais árduos da pesquisa acadêmica.

É interessante também apontar dois conceitos diferenciados do método da história oral. O primeiro é o de autoria, uma vez que, diferentemente da área de Comunicação, é considerado depoente o autor da narrativa e não o entrevistador - daí o protocolo da obtenção da cessão de uso (MARTINEZ, 2008, p. 28). Outra questão bem resolvida pelos historiadores é a de que se trata de uma versão do fato, e não de uma verdade absoluta. Não raro, esta versão é romanceada, numa tentativa imaginativa, consciente ou não, de "salvar a preciosa consciência da injustiça do mundo ${ }^{3}$. O termo empregado para esta questão, idealizado em 1973 pelo historiador italiano Alessandro Portelli, é o de ucronia, no sentido de uma utopia sobre o passado ou, como ele diz, "uma expressão narrativa possível de recusa da ordem da realidade existente. (...) A forma ucrônica permite ao narrador 'transcender' a realidade dada e recusar ser identificado e satisfeito com a ordem existente" (PORTELLI, 1991, p. 108) ${ }^{4}$. "Ucronia, assim, economiza a preciosa consciência da injustiça do mundo existente, porém fornece os meios de resignação e de reconciliação" (PORTELLI, 1991, p. 116). "Embora ventile as chamas de descontentamento por revelar a contradição da realidade e desejo, ele ajuda a manter essa contradição de sair de um conflito aberto" (idem).

Uma extensão mais recente da história oral, a história familiar, une a diversidade antropológica à dinâmica histórica e às técnicas de observação sociológicas para compreender a família - rede de relações que a maioria das pessoas está conectada na maior parte de sua vida, formada por laços de afetos, codependência e solidariedade moral. São estes vínculos, com sua infindável variedade de padrões, as suas convergências e dissonâncias, bem como a forma como se desenrolam ao longo do tempo histórico, o alvo das histórias familiares.

O desafio do método, portanto, é que da análise dos dados brote uma compreensão que faça sentido do ponto de vista sociológico, transcendendo simplesmente a visão dos

3 Do original: "Uchronia, thus, saves the precious awareness of injustice of the existing world, but supplies the means of resignation and reconciliation. While it fans the flames of discontent by uncovering the contradiction of reality and desire, it helps to keep this contradiction from breaking out as an open conflict" (PORTELLI, 1991, p. 116).

4 “(...) uchronia as one possible narrative expression of refusal of the existing order of reality (...). The uchronic form allows the narrator to 'transcend' reality as given and to refuse to be identified and satisfied with the existing order" (PORTELLI, 1991, p. 108). 
indivíduos envolvidos. Um expoente do método, o britânico Paul Thompson diz que "não obstante o papel crucial desempenhado na transmissão da cultura pela educação, religião, política ou outros canais, a família continua a ser hoje o principal canal para a transmissão de muitos dos aspectos fundamentais da cultura e identidade: incluindo idiomas, nomes, terra e moradia, posição social local, a observação religiosa, valores e aspirações sociais, habilidades domésticas, compromissos com a família e com os outros, e 'hábitos do coração' - atitudes em relação a emoções e relacionamentos" (BERTEAUX; THOMPSON, 2009, p. vii).

Para o pesquisador da Universidade Autônoma do México, Jorge González, esta abordagem “(...) requer necessariamente informação sobre várias gerações - no mínimo, três - e a obtenção de registros de múltiplas fontes: orais, escritas, iconográficas, documentais etc., os mais detalhados possíveis (...)" (GONZÁLEZ, 1995, p. 65). Segundo González, esta janela deve, no mínimo, "conter de doze a vinte pessoas para que se possa trabalhar adequadamente" (idem, p. 70). As informações são levantadas em três níveis principais: uniões - a relação entre cônjuges -, filiação - a relação entre parentes e filhos -; e laços filiais - a relação entre irmãos (BERTAUX; DELCROIX, 2000). Por meio deste levantamento emergem os padrões de "regras, valores, hábitos, condutas, estratégias, fracassos, conflitos e transmissões através do tempo e de uma geração à outra" (GONZÁLEZ, 1995, p. 65). Os dados colhidos são registrados em fichas (hoje digitais), a partir das quais é feita a análise. Para se ter uma visão do conjunto das relações, sugere-se a elaboração de um genograma, gráfico que permite observar os dados coletados de forma visual, sintética e sincrônica (idem, p. 77).

O método é importante para a compreensão de fenômenos como o de mobilidade social, uma vez que fatores externos (como desastres naturais), sociais (caso de guerras e migrações), sanitários (epidemias, fomes), ecológicos (esgotamento de recursos) e outros podem atrasar ou mesmo impedir a mobilidade social (GONZÁLEZ, 1995, p. 77). Desta maneira, a coleta da história familiar resgata ou permite a observação das trajetórias humanas no contexto socio-histórico. "Assim como casamentos rompem e empresas vão à falência, da mesma forma sociedades inteiras podem ser reformuladas ou divididas por meio da revolução, guerra ou desintegração de impérios (BERTEAUX; THOMPSON, 2009, p. 1-2). Neste cenário, os indivíduos "nadam em águas ora suaves, ora turbulentas. Alguns podem florescer em nichos familiares herdados, enquanto outros vão neles morrer de fome" (idem). Além destes, os autores lembram que é preciso incluir também "aqueles que optam por emigrar em busca de uma vida melhor, aqueles que se deslocam para escapar de armadilhas

5 (...) "notwithstanding the crucial roles played in the transmition of culture by education, religion, politics or other channels, the family remains today the main channel for the transmission of many of the fundamental aspects of culture and identity: including languages, names, land and housing, local social standing, religious observation, social values and aspirations, domestic skills, commitments to kin and to others, and 'habits of the heart' - attitudes to emotions and relationships" (BERTEAUX; THOMPSON, 2009, p. vii). 
econômicas, ou aqueles impulsionados a adaptar-se pela turbulência da revolução, fugindo da perseguição, guerra ou morte" (BERTEAUX; THOMPSON, 2009, p. 1-2) .

Para Thompson e para o sociólogo francês Daniel Bertaux, estes fenômenos "são essenciais para o próprio metabolismo e normatizações fundamentais da sociedade, tanto para a sua continuidade quanto mudança ao longo do tempo (BERTEAUX; THOMPSON, 2009 , p. 1). Segundo eles, é por meio deste processo que "as estruturas sociais básicas da classe, status e situs (ramos da indústria) são reproduzidas e transformadas, surgem ou desaparecem; que as próprias sociedades avançam, se consolidam ou se fragmentam" (idem). Mas não somente. É também por meio deste processo que "as instituições e as empresas recrutam, que as famílias lançam suas crianças, que as pessoas imaginam e buscam a realização pessoal em suas vidas" (BERTEAUX; THOMPSON, 2009, p. 1). ${ }^{7}$

Neste sentido, a família não é apenas um sistema de consumo e convivência, mas também uma unidade de produção. Este fenômeno ocorre por meio de toda uma gama de orientações e atividades estruturadas numa base diária que, muitas vezes, se prolonga por toda a vida - e às vezes além dela, no caso de heranças morais e materiais. Assim, as energias de seus membros são produzidas e reproduzidas, culminando num processo antroponômico, isto é, que resulta na produção e transformação dos próprios seres humanos (BERTAUX; DELCROIX, 2000). Transformar uma criança em um ser plenamente socializado demanda imensa energia, o que impacta fortemente na vida dos pais e casais (idem, p. 78-79). Sendo que, como se sabe, a energia investida não tem necessariamente um resultado proporcional assegurado.

\section{O uso da história de vida em Comunicação}

Nos estudos de comunicação, segundo a docente do PPGCOM da UFRGS, Nilda Jacks, "embora a família seja um grupo privilegiado, o uso desta técnica ainda é bastante escassa, em particular nos estudos de recepção" (JACKS, 2002).

6 "Just as marriages breaks and firms go bankrupt, so whole political societies may be recast or split through revolutions, war, or dissolution of empires. Individuals swim in waters now benign, now turbulent. Some may flourish in an inherited family niche, while others will starve in the same way. Against those who succeed or fail through transmission, we need to set those who choose to immigrate in search of a better life, those who move to escape an economic trap, or those driven to adapt by the turmoil of revolution, fleeing from persecution or war, and death" (BERTEAUX; THOMPSON, 2009, p. 1-2).

7 "Social mobility processes are integral to the very metabolism and core regulations of society, both to their continuity and change over time. It is through such processes that basic social structures of class, status, and situs (branches of industry) are reproduced and transformed, emerge or disappear; that societies themselves move forward, consolidate or splinter, that institutions and enterprises recruit, that families launch their children, that individuals imagine and seek personal fulfillment in their lives" (BERTEAUX; THOMPSON, 2009, p. 1). 
Do ponto de vista de Comunicação, a história de vida, em qualquer de suas modalidades, não é decerto um método pouco empregado. Certamente por ser bastante exigente, contudo, ele é usado com uma frequência menor do que a princípio se poderia supor. Não se tem como objetivo aqui analisar o conteúdo dos artigos, mas apenas apresentar um dado quantitativo para efeito de contextualização, usando para isso rastreamento feito no Portcom (Portal de Livre Acesso à Produção em Ciências da Comunicação), que disponibiliza a produção científica da Sociedade Brasileira de Estudos Interdisciplinares da Comunicação (Intercom). Dos 18.235 trabalhos apresentados em eventos disponibilizados neste repositório em 5 de novembro de 2013, uma busca simples pela palavra-chave "história de vida", no campo "trabalhos em eventos", revela apenas dois resultados ${ }^{8}$.

Se o termo for colocado no plural, "histórias de vida", a busca produz resultados não muito mais generosos: 8 trabalhos ${ }^{9}$.

Esta triagem resulta no levantamento de dados positivos, como o fato de que o método $\boldsymbol{e}$ usado em praticamente todas as regiões do país, salvo a Norte. Contudo, se rastrearmos da mesma forma (busca no campo de trabalhos apresentados da Portcom) os termos que constam do livro Métodos e Técnicas de Pesquisa em Comunicação (DUARTE; BARROS, 2005), os resultados são interessantes: Pesquisa Bibliográfica (0); Entrevista em Profundidade (1); Método Biográfico (0) - sendo que Biografia (13), Perfis (23), Narrativas Biográficas (3); Narrativa Biográfica (1) -; Etnografia (32); Folkcomunicação (204); Observação Participante (5); Pesquisa-Ação (7); Pesquisa de Opinião (22); Grupo Focal (5); Semiótica (379); Estudo de Caso (298); Auditoria da Comunicação (0); Análise Documental (1); Análise de Conteúdo (72); Análise do Discurso (169); Análise Hermenêutica (1); Análise de Imagem (3); Auditoria de Imagem (7).

Esta triagem evidentemente permite múltiplas leituras, mas se adotarmos o princípio de simplicidade de Ockham ${ }^{11}$, podemos propor algumas deduções. A primeira $\boldsymbol{e}^{\mathrm{a}}$ saudável profusão de métodos e técnicas desfrutada na área de Comunicação, que per se causa certa pulverização dos resultados. A segunda $\boldsymbol{e}^{\text {a }}$ Babel de nomes pelos quais

8 São eles: (CESAR; JURKVICZ; MIANI, 2009), da UEL (Universidade Estadual de Londrina), e (GUERIN, 1999), da UFRS (Universidade Federal do Rio Grande do Sul).

9 O resultado consta de um total de 11 trabalhos, contudo três foram descartados por se tratarem de resenhas.

10 São eles: (CASTRO, 2012), da UFC (Universidade Federal do Ceará); (MUSSE; ARANTES, 2012), da UFJF (Universidade Federal de Juiz de Fora); (FONSECA; SIMÕES, 2011), da UFMG (Universidade Federal de Minas Gerais); (FORNAZARI; SOUZA, 2010), da UEPG (Universidade Estadual de Ponta Grossa); (KUNSCH, MARTINEZ, 2007), da UniFIAAM/Faculdade Cásper Libero; (ROCHA, 2007), da PUC-SP (Pontifícia Universidade Católica de São Paulo). (MARTINEZ; CRIADO), 2006), da UniFIAAM/USP (Universidade de São Paulo) e (DIAS, 2003), da UFPB (Universidade Federal da Paraíba).

11 Do monge medieval inglês William de Ockham (1285-1347). 
são conhecidos estes métodos e técnicas, como a própria história de vida, que pode estar registrada por variados termos. A terceira, para não nos prolongarmos demasiado, $\boldsymbol{e}$ uma evidente falta de padronização dos conteúdos marcados no campo das palavras-chave, que às vezes estão mais alinhados com as linhas de programa e de pesquisa do que necessariamente com o estudo em si. A grande disparidade entre o número de trabalhos do Portcom (18.235) e a pequena proporção de trabalhos que pode ser rastreada pelo método empregado sugere também a tradição da comunidade científica comunicacional brasileira em produzir artigos teóricos, que não necessariamente empregam métodos ou técnicas empíricos de levantamento de dados. Ou, também, que por vezes apenas uma técnica pode não ser suficiente para dar conta do fenômeno, sendo necessário um conjunto delas para a realização da pesquisa.

Algumas revistas científicas, em suas diretrizes para autores, recomendam que a metodologia empregada seja explicitada durante o preenchimento das palavras-chave. Mas são poucas. A pressão enfrentada pelos programas, sobretudo os com nota acima de 5 , no quesito internacionalização, talvez estimule a prática de se explicitar os bastidores da pesquisa ou de se encorajar a produção de estudos empíricos, modalidade valorizada na comunidade anglo-saxã.

\section{Reflexões sobre o uso em Comunicação}

Do ponto de vista da usabilidade, o emprego deste método em Comunicação pede alguns cuidados para que não se produza apenas mais uma entrevista superficial. O primeiro é a sólida pesquisa prévia sobre estado da arte ou o campo da pesquisa. Há que se cuidar também da seleção de bons narradores. Como na prática do documentarista brasileiro Eduardo Coutinho, podem ser necessárias entrevistas exploratórias para escolha adequada do protagonista da narrativa (LINS, 2004). Outro cuidado é o pacto de clareza com o entrevistado, como propõe o estudioso de Jornalismo Literário estadunidense Mark Kramer (1995). Entende-se o entrevistado como um colaborador que tem o direito de optar por participar ou não do projeto. E deve ter ciência prévia do uso do material, sob o risco de a pesquisa se tornar um instrumento de coação.

Diferentemente da entrevista jornalística, em geral mais breve, a coleta de uma história de vida pressupõe necessariamente um entrosamento maior com o entrevistado, visto que a entrevista pode ser única, seriada ou múltipla; estimulada ou não com fotos, vídeos e outros documentos em geral; diretivas (com auxílio de uma pauta previamente elaborada com perguntas ou questionários) ou abertas; longas ou breves. Cada caso revelará a abordagem ideal. Qualquer caminho escolhido, o importante é que se crie um 
campo para o diálogo de fato (MEDINA, 1990), um caminho para a tentativa de compreensão profunda do outro.

A gravação do encontro deve ter seus prós e contras bem pesados, como o tempo que se leva para a decupagem (normalmente na proporção de três horas de trabalho para cada hora gravada) versus a fidelidade do registro que o recurso proporciona. Como as pesquisas em Comunicação têm ciclos longos, variando de um ano em iniciação científica há quatro anos em doutorados, o argumento pesa em favor de se adotar o procedimento.

Finalmente, algo que diferencia o pesquisador da área de Comunicação é o pressuposto de que ele domina, pelo menos em alguma medida, as artes da escrita. Deve-se, sim, ter o cuidado de ser fiel ao depoimento, mas é mandatório um texto de qualidade, cuja leitura seja fluente e envolvente.

Finalmente, a adoção de uma prática das outras áreas pode ser bem-vinda: a fase pós-entrevista, quando pode ocorrer a validação (e/ou eventual veto parcial ou integral) do material junto ao entrevistado. Esta devolutiva, não raro envolta em um clima emotivo, humaniza um processo que já é sensível por natureza. Afinal, para muitos entrevistados, a história de vida é a única coisa que verdadeiramente possuem. Não incluir esta ação no planejamento pode caracterizar a pesquisa como uma forma de exploração, sem que o indivíduo ou comunidade consultados se beneficiem dos resultados obtidos.

É preciso que o pesquisador da área de Comunicação tenha consciência, também, a respeito da questão ética da manutenção (ou não) de vínculos posteriores, como bem descobriu o jornalista estadunidense Joseph Mitchell (1908-1996) ao desenvolver perfis que levavam até três anos para serem escritos para a revista The New Yorker (MITCHELL, 2003). O mais provável é que o vínculo seja criado - desejando-se ou não -, portanto é preciso que o pesquisador esteja consciente para a forma como fará (ou não) o cultivo dele.

\section{Considerações}

Lidar com histórias de vida, ou com qualquer método qualitativo, não é uma opção simples, pois há muitas variáveis e incertezas envolvidas no emprego da técnica. Como bem lembra a pesquisadora da área Maria Immacolata Vassallo de Lopes, nas Ciências Sociais, "o próprio objeto é dinâmico e mutável porque os problemas estudados são fenômenos históricos, institucionais, relações de poder, classes sociais, manifestações culturais etc." (LOPES, 2012, p. 37). Por isto, o que muda, de pesquisa para pesquisa, não é simplesmente o dado, o objeto ou o próprio pesquisador, mas “as próprias 'verdades' e 'comprovações’ produzidas por essas ciências” (idem). Daí, 
segundo ela, se reconhecer que o conhecimento científico do campo se articula por rupturas, descontinuidades e crises. E o aceite de mudança de paradigmas pela comunidade científica, como já apontou o físico estadunidense Thomas Kuhn (1922-1996), não é um processo fácil.

Acima de tudo, no entanto, este trabalho sugere a inegável riqueza que se encontra por trás deste método ou técnica - afinal não há um consenso entre os autores consultados. Não são apenas múltiplos os nomes ou vertentes pelos quais a história de vida é chamada, da história oral à familiar. No contexto complexo desta multiplicidade, fica o desafio de se tentar compreender a mais profunda e, por vezes, indecifrável fronteira do conhecimento: o próprio ser humano. Neste sentido, e enquanto as incertezas pessoais, sociais, cosmológicas se perpetuarem - e é essa inquietação que move a Ciência -, não há dúvida de que há e haverá um grande potencial de uso deste método não só em Comunicação, mas em todas as demais áreas científicas.

\section{Referências}

AGEE, James; EVANS, Walker. Elogiemos os Homens Ilustres. São Paulo: Cia das Letras, 2009.

ASA (AMERICAN SOCIOLOGICAL ASSOCIATION). Robert Ezra Park. 22 mar 2005. Disponível em:

$<$ http://www2.asanet.org/governance/park.html>. Acesso em: 24 out 2013.

BAITELLO Jr., Norval. A Era da Iconofagia: ensaios de comunicação e cultura. São Paulo: Hacker, 2005.

BECKER, Howard S. Métodos de Pesquisa em Ciências Sociais. 4ª ed. São Paulo: Hucitec, 1999, p. 101-116.

BERTAUX, Daniel; DELCROIX, Catherine. "Case histories of families and social processes: enriching sociology”. In: CHAMBERLAYNE, Prue; BORNAT, Joanna; CAPRINO, M. P. ; PERAZZO, P. F. História oral e estudos de comunicação e cultura. Revista FAMECOS (Online), v. 18, p. 801-815, 2011. Disponível em: <http://repositorio.uscs.edu.br/bitstream/123456789/247/2/1038537636-1-PB.pdf $>$. Acesso em: 5 nov 2013.

BERTEAUX, Daniel. Narrativas de Vida: a pesquisa e seus métodos. São Paulo: Paulus, 2010.

; THOMPSON, Paul (Ed.). Between Generations: Family Models, Myths and Memories. $3^{\text {rd }}$ edition. Oxford: Oxford University Press, 2009, p. 1-12.

.Pathways to Social Class: a qualitative approach to social mobility. Oxford: Oxford University Press, 1997.

; THOMPSON, Paul (Eds). Pathways to Social Class: a qualitative approach to social mobility. Oxford: Oxford University Press, 2006.

BOSI, Ecléa. Memória e Sociedade: lembranças de velhos. $3^{\text {a }}$. edição. São Paulo: Companhia das Letras, 1994. 
O Tempo Vivo da Memória: ensaios de psicologia social. 2a . edição. São Paulo: Atelier Editorial, 2003.

BUITONI, Dulcília Schroeder. Texto-documentário: espaço e sentido. 1986. Livre-Docência. São Paulo, ECA-USP, 1986.

DELCROIX, Catherine; INOWLOCKI, Lena. Biographical Research as a Cognitive and Practical Approach for Social Workers: An Interview with Catherine Delcroix [37 paragraphs]. Forum Qualitative Sozialforschung/Forum: Qualitative Social Research, 9 (1), Art. 60, 2008. Disponível em: $<\mathrm{http} / /$ nbn-resolving.de/urn:nbn:de:0114-fqs0801600>. Acesso em: 31 out 2013.

DIEHL, Astor Antonio; TATIM, Denise Carvalho. Pesquisa em Ciências Sociais Aplicadas: métodos e técnicas. São Paulo: Pearson Prentice Hall, 2004.

DUARTE, Jorge; BARROS, Antonio. Métodos e Técnicas de Pesquisa em Comunicação. São Paulo: Atlas, 2005.

ERBOLATO, Mário. Técnicas de Codificação em Jornalismo. Petrópolis: Vozes, 1984.

GOLDENBERG, Miriam. A Arte de Pesquisar: como fazer pesquisa qualitativa em ciências sociais. Rio de Janeiro: Record, 1999.

GONZÁLEZ, Jorge Alejandro. Histórias de famílias entre o tempo histórico e o tempo biográfico: estratégias, objeto e método. Comunicação e Sociedade, São Bernardo do Campo, n. 27, p. 61-83, jan. 1997.

GROSSBERG, Laurence. Caught in the Crossfire: Kids, Politics and America's Future. Boulder: Paradigm, 2005.

HASLETT, Adam. A Poet's Brief. In: AGEE, James; EVANS, Walker. Cotton Tennants: Three Families. Brooklyn/New York: The Baffler and Melville House, 2013.

HOBSBAWN, Eric. A Era dos Extremos: o breve século XX - 1914-1991. São Paulo: Companhia das Letras, 2008.

IBGE/PNAD. Uma análise de vida das condições da população. Disponível em: <ftp://ftp.ibge.gov.br/ Indicadores_Sociais/Sintese_de.../SIS_2012.pdf>. Acesso em: 20 jun 2013.

JACKS, N. A. Historia de família y etnografia: procedimientos metodológicos para un análisis integrado. In: Guillermo Orozco Gomez. (Org.). Recepción y mediaciones. Casos de investigación en América Latina. 1ed. Buenos Aires: Grupo Editorial Norma, 2002, v. 20, p. 25-46.

História de Familia \& "Grounded Theory”. In: XXIII Congresso Brasileiro de Ciências da Comunicação. Intercom, 23, 2000, Manaus (AM). São Paulo: Intercom, 2000. Disponível em: $<$ http://www.portcom.intercom.org.br/pdfs/6167624d3dee3a4afa8f17308e1941c6.pdf>. Acesso em: 6 nov 2013.

KRAMER, Mark. Breakable Rules for Literary Journalists. In: SIMS, Norman; KRAMER, Mark. Literary Journalism: A New Collection of the Best American Nonfiction . Nova York: Ballantine Books, 1995, p. 21-34. 
KUHN, Thomas. A Estrutura das Revoluções Científicas. São Paulo: Perspectiva, 1982.

LIMA, Edvaldo Pereira. História de Vida. In: Páginas Ampliadas: o livro-reportagem como extensão do Jornalismo e da Literatura. Barueri/São Paulo: Manole, 2009, p. 114-120.

LINS, Consuelo. O Documentário de Eduardo Coutinho: televisão, cinema e vídeo. Rio de Janeiro: Jorge Zahar, 2004.

LOPES, Maria Immacolata Vassallo de. Pesquisa em comunicação. 11. ed. São Paulo: Loyola, 2012.

MARCONI, Marina de Andrade; LAKATOS, Eva Maria. Técnicas de Pesquisa: planejamento e execução de pesquisas, amostragens e técnicas de pesquisa, elaboração, análise e interpretação de dados. $7^{\text {a }}$. ed. São Paulo: Atlas, 2012, p. 122-126.

MARTINEZ, Monica. Jornada do Herói: estrutura narrativa mítica na contrução de histórias em jornalismo. São Paulo: Annablume/Fapesp, 2008.

MEDINA, Cremilda. Entrevista: o diálogo possível. 2. ed. São Paulo: Ática, 1990.

MEIHY, José Carlos Sebe Bom. Manual de história oral. 2. ed. São Paulo: Loyola, 1998.

; RIBEIRO, Suzana L. Salgado. Guia Prático de História Oral - Para Empresas, Universidades,

Comunidades e Famílias. São Paulo: Contexto, 2011. MITCHELL, Joseph. O segredo de Joe

Gould. São Paulo: Cia das Letras, 2003.

PORTELLI, Alessandro. Uchronic Dreams: Working-Class Memory and Possible Worlds. In: PORTELLI, Alessandro. The death of Luigi Trastuli and other stories: form and meaning in Oral History. New York: State University of New York Press, 1991.

REMNICK, David (ed.). Life Stories: Profiles from the New Yorker. New York: Random House, 2000.

SEVERINO, Antônio Joaquim. Metodologia do trabalho científico. 23. ed. rev. e atual. São Paulo: Cortez, 2007.

THOMAS, William Issac; Znaniecki, Florian. The Polish peasant in Europe and America: monograph of an immigrant group. Boston: Richard G. Badger, The Gorham Press: 1918-1920. Disponível em: $<$ http://chla.library.cornell.edu/c/chla/browse/title/3074959.html>. Acesso em: 24 out 2013.

THOMPSON, Paul. A Voz do Passado: história oral. $3^{\text {a }}$. edição. Rio de Janeiro: Paz e Terra, 2002.

\section{Trabalhos citados}

CASTRO, Henrique Sérgio Beltrão de. No tempo do rádio: sempre! Histórias de Vida e Formação, afetividade e extensão universitária no ar. XXXV Congresso Brasileiro de Ciências da Comunicação - Intercom, 35, 2012, Fortaleza, CE. São Paulo: Intercom, 2012. Disponível em: <http://www. portcom.intercom.org.br/pdfs/82582712958835071037170038566568615252.pdf $>$. Acesso em: 5 nov 2013.

CÉSAR, Regina Célia Escudero; JURKEVICZ, Maristela Romagnole de Araújo; MIANI, Rozinaldo Antonio. A contribuição da comunicação comunitária nos processos de organização popular. 
XXXII Congresso Brasileiro de Ciências da Comunicação - Intercom, 32, 2009, Curitiba, PR. São Paulo: Intercom, 2009. Disponível em: < http://www.intercom.org.br/papers/nacionais/2009/ resumos/R4-3720-1.pdf>. Acesso em: 5 nov 2013.

DIAS, Suelly Maria Maux. Imprensa feminina, folhetim e histórias de vida. XXVI Congresso Brasileiro de Ciências da Comunicação - Intercom, 26, 2003, Belo Horizonte, MG. São Paulo: Intercom, 2003. Disponível em: <http://www.portcom.intercom.org.br/pdfs/119913146932227629091564706117 135757029.pdf $>$. Acesso em: 5 nov 2013.

FORNAZARI, Emmanuel Victor Schactae; SOUZA, Carlos Alberto de. O Sorriso da Esperança: um livro-reportagem sobre histórias de vida de crianças com Leucemia.

GUERIN, Yhevelin. A História de Vida no Estudo de Recepção. XXII Congresso Brasileiro de Ciências da Comunicação - Intercom, 22, 1999, Rio de Janeiro, RJ. São Paulo: Intercom, 1999. Disponível em: $<$ http://www.portcom.intercom.org.br/pdfs/94325c433cffeefcb3e5d4e0cf7b0d4e.PDF>. Acesso em: 5 nov 2013.

KÜNSCH, Dimas A.; MARTINEZ, Monica. Histórias de vida produzidas por jornalistas-escritores para público juvenil: estudo de caso da coleção Heróis e Campeões. XXX Congresso Brasileiro de Ciências da Comunicação - Intercom, 30, 2007, Santos, SP. São Paulo: Intercom, 2007. Disponível em: <http://www.intercom.org.br/papers/nacionais/2007/resumos/R0682-1.pdf $>$. Acesso em: 5 nov 2013.

MARTINEZ, Monica; CRIADO, Alex. Estudo de Caso das Oficinas de Comunicação e Expressão do Projeto História Ambiental da Bacia do Rio Aricanduva e Córrego Itaquera. XXIX Congresso Brasileiro de Ciências da Comunicação - Intercom, 29, 2006, Brasília, DF. São Paulo: Intercom, 2006. Disponível em: <http://www.portcom.intercom.org.br/pdfs/1199131469322276290915647 06117135757029.pdf $>$. Acesso em: 5 nov 2013.

MUSSE, Christina Ferraz; ARANTES, HaydêeSant'Ana. Telejornalismo e memória: narrando a cidade pelas histórias de vida. XXXV Congresso Brasileiro de Ciências da Comunicação - Intercom, 35 , 2012, Fortaleza, CE. São Paulo: Intercom, 2012. Disponível em: <http://www.intercom.org.br/ papers/regionais/sudeste2011/resumos/R24-0523-1.pdf >. Acesso em: 5 nov 2013.

ROCHA, Debora Cristine. A biografia da tela. XXX Congresso Brasileiro de Ciências da Comunicação Intercom, 30, 2007, Santos, SP. São Paulo: Intercom, 2007. Disponível em: <http://www.intercom. org.br/papers/nacionais/2007/resumos/R1411-1.pdf>. Acesso em: 5 nov 2013.

\footnotetext{
$90 \frac{\text { Comunicação \& Inovação, PPGCOM/USCS }}{\text { v. 16, n. } 30 \text { (75-90) jan-abr } 2015}$
} 